Ola Magntorn is a lecturer in biology and geology at Kristianstad University. He has a teacher education for upper secondary school and he has worked as a teacher in both compulsory school and upper secondary school. Since 2002 he is associated to the national graduate school in science and technology education (FontD) at Linköping University. His main focus of research is on ecology education and the ability to read nature.

Gustav Helldén is a professor of science education at Kristianstad University. He has long experience of teaching in schools as well as in teacher education. His main focus of research is on students understanding of ecological processes.

\title{
OLA MAGNTORN
}

Kristianstad University, Sweden

ola.magntorn@mna.hkr.se

\section{Reading Nature- experienced teachers' reflections on a teaching sequence in ecology: implications for future teacher training}

\begin{abstract}
This article explores experienced primary teachers views on teaching for 'reading nature'. The concept 'reading nature' has to do with an ability to recognise organisms and relate them to material cycling and energy flow in the specific habitat which is to be read. It has to do with the natural world that we face outside and the tools we have are our experiences from previous learning situations both in and out-of-doors. The teachers were asked to comment on the content of a CD-ROM with teaching sequences from a primary class studying a river ecosystem. Perceptions that teachers held were found to be supportive but complex and varied regarding the possibilities and advantages of implementing this type of teaching design in the everyday classroom. The paper finishes by identifying some implications for teacher training to support fieldwork and ecological literacy in primary schools in the future.
\end{abstract}

\section{INTRODUCTION}

In recent years, there has been a growing concern about the substantial decrease in opportunities for outdoor learning in schools (e.g. Dillon et al., 2006; Rickinson et al., 2004; Slingsby \& Tilling, 2002) and the limited knowledge students have of our common animals and plants in the nearest environment (e.g. Bebbington, 2005). In the national curriculum for compulsory school in all Nordic countries there are explicit paragraphs saying that primary school students (up to year 5) should be taught about common animals and plants and about their environmental demands. It is also stressed that students should be taught about different ecosystems. However, in these curricula there are no explicit guidelines for how this instruction is supposed to be carried out and naturally there is a great variation in how teachers meet these demands.

In a previous study of 'reading nature' we designed and evaluated a teaching sequence following a class of primary school students and their developing ability to read nature (Magntorn \& Helldén, 2005). The present paper is a follow up study where we discussed, with experienced practitioners, 
the teaching sequence in relation to its possibilities and limitations for implementation in everyday school activities. We also discussed their views of the concept 'reading nature' in relation to the national curriculum in biology education. The aim was to elicit critical aspects supporting or hindering the implementation of such a teaching design in the everyday classroom. We believe it is valuable to bring the science education research tradition closer to the world of school, where teachers with a didactical interest and with a long teaching experience can contribute with important aspects, helping to bridge the gap between research results and implementation to classroom practice. Our aims are supported by a large review on research on outdoor learning (Rickinson et al., 2004) where the authors are demanding more research in what they call "blank spots of research" One of these blank spots is "teachers and outdoor educators' conceptions of "the outdoor classroom" and the curricular aims and pedagogical strategies that they see as important for effective teaching therein"(p 56).

Leach and Scott (2002) claimed that most studies so far have focused on students' learning but there has been little focus on the importance of the teachers' role in science education and the teachers' view of learning. There are relatively few metacognitive studies on teachers view on the design of instruction. In order to implement a successful teaching design in the everyday classroom we believe it is of great importance to hear the voices of teachers with long experience. Regarding studies on teaching design there are, however, critical voices heard about the validity of such studies and several researchers have described the development of teaching sequences not as educational research but rather as developmental studies (Lijnse, 2000; Anderson \& Hogan, 1999). But this is changing and today there is a growing support for seeing the evaluated teaching sequence as a research result (e.g. Meheut \& Psillos, 2004). This research tradition is relatively young but the trade of designing teaching sequences is of course long and what teachers have always done. Despite this experience the tradition of publishing and disseminating it in a fruitful way is unfortunately not so well developed. Lijnse (2000) writes "The primary aim of science education research is content-specific didactical knowledge, based on developing and justifying exemplary science teaching practices". We believe our research can contribute to this aim.

\section{Reading nature}

The ability to 'read nature' is central in this work. It is described by Magntorn and Helldén (2005), but needs a brief explanation here as well. We see it as an important aspect of ecological literacy which is ideally about developing a rich knowledge base and multifaceted beliefs and/or philosophies about the environment which lead to ecological sustainability (Orr, 1992). Our phrase 'reading nature' focuses on ecology and the outdoor context. It has to do with an ability to recognise organisms and relate them to material cycling and energy flow in the specific habitat which is to be read. It has to do with the natural world that we face outside and the tools we have are our experiences from previous learning situations both in and out-of-doors. In this context it has to do with students' ability to give a relevant interpretation of the river as an ecosystem based on recognition of common organisms and awareness of their autecology together with an understanding of the relationships between functional groups and how abiotic factors, such as light and speed of water, influence the whole ecosystem.

\section{Methods}

The teaching was carried out in a grade 3-4 class (yrs 10-11) with 23 students. The school is a state school (non-fee paying) in a middle class community in southern Sweden. It is important to say that the instruction was conducted by a teacher from the local nature school (i.e. a field study centre with experienced outdoor educators, who, free of charge, visit classes in the municipality) together with the ordinary class teacher. The overall teaching sequence comprised 4 phases spanning 7 lessons of varied duration from 80 to 200 minutes (see figure 1). 
All the teaching activities were video recorded. Although it was necessary to limit the total duration of the video clips to 40 minutes, so as to ensure reasonable total viewing time, strenuous efforts were made to maintain the flow and the general essence of the lessons. Field work and classroom activities with collaboration and task solving activities which dominated the instruction also dominated the film. The idea was to give the viewer an idea of what was taught, how it was taught and of the reaction from the students. Students writing and drawing activities were also part of the film. The two teachers involved, were asked to validate the content of the video and both where positive. The class teacher said: "It is representing the progression very well and it gives a representative image of the activities and the learning situations- Yes, I think it shows the activities in a good way".

Each respondent was given a CD-ROM, consisting of the video together with a short background note about reading nature as a concept and a questionnaire with the questions discussed in the follow up interview. The interviews were semi-structured and followed guidelines from Kvale (1997). Each interview lasted between 50 and 70 minutes. The interviews were conducted by one of the researchers, the first author, and the analysis was done by both of the researchers. For reasons of transparency and hopefully of interest for the reader, the film is now available on mms://194.47.25.160/mna/vramsafilmen.wmv

\section{Description of the respondents}

There were altogether 13 respondents ( 1 male and 12 females, which mirror the distribution according to sex among the primary teachers in the municipality). The selection of respondents was made in cooperation with the local pedagogical centre in the municipality. The researchers asked them to select experienced primary school teachers without specialisation in science, but with interest and experience in outdoor education. Another criterion was that they should be reflective and willing to critically discuss learning and teaching issues. The respondents had at least 15 years of teaching experience and along with a majority of the primary school teachers in the municipality, they were familiar with the nature school and its methods and ideas. Six of them (R 1-6) were teachers with a part time engagement supervising or giving educational support to other teachers in the municipality. Their specialities were ICT, language or mathematics. The other seven teachers in the group (R 7-13) were teaching primary classes all the theoretical school subjects without any specialisation.

Space constraints make it necessary to present summaries of the respondent answers supplemented by the comments from three respondents in more detail. These three were chosen by the researchers since they had different challenges in their everyday teaching situation. Respondent 1 (R1) had long experience of teaching in an urban school with a mix of students from different social groups. The access to different ecosystems was limited and within walking distance it was restricted to parks or other "domesticated nature". Respondent 2 (R9) was teaching in a small school in a residential district. The near surroundings of the school were varied with access to several different ecosystems, such as rivers, forests and the sea, within walking distance. Respondent 3 (R12) had long experience from teaching in a school within an area dominated by multi-storey buildings and with a strong dominance of immigrants in the classes. Within walking distance they had access to small groves, small streams and open grasslands. The municipality is dominated by an open agricultural landscape with deciduous forests in the higher terrain.

\section{The teaching sequence in outline}

The teaching design had a bottom-up approach (i.e. starting with one organism and scaffolding an ecosystems understanding around this single organism). The key organism; a freshwater shrimp (Gammarus pulex) was introduced early. Its ecology was studied in some depth and its relations to other populations were investigated. This was followed by more abstract reasoning e.g. presenting models such as food pyramids or food chains, where the freshwater shrimp together with other 
organisms found were continuously referred to. Students' prior ideas were often challenged by the teacher or by peers when they worked in small groups solving different tasks both in the field and in the classroom. In general there was a mix of outdoor and classroom activities during every teaching event.

Phase 1: Autecology (i.e. the ecological relationships of a particular plant or animal species) of the freshwater shrimp. The collection of the animal in the river was followed by an event of brainstorming when students were asked to come up with questions about the shrimp. These questions could be about its morphology or about functional or behavioural features which could be studied by observation or experimentation. The relevant questions and the conclusions from all the observations were summarised by the teacher on the white board.

Phase 2: Taxonomy: (i.e. identification and grouping of animals) and autecology. The class collected different organisms in fast and in slow sections of the stream and studied their adaptations to the environment. Herbivores and predators were determined according to their morphology and behaviour. Life cycles were discussed and in small groups the students made sealed aquatic ecosystems. The futures of these were discussed according to the roles of plants, animals and abiotic factors such as light and air.

\section{Phase 4: Systemic level The relations between the shrimp and the living and the non living world. Cycling of matter and flow of energy<smiles>C1CCCC1</smiles>

\section{Phase 3: Synecology} The relations between the shrimp and other populations.

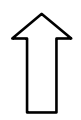

\section{Phase 2: Taxonomy and autecology.}

Several organisms and their life cycles and adaptation to the environment is studied<smiles>C1CCCC1</smiles>

\section{Phase 1: Intro}

Focus on one organism - The freshwater shrimp and its autecology
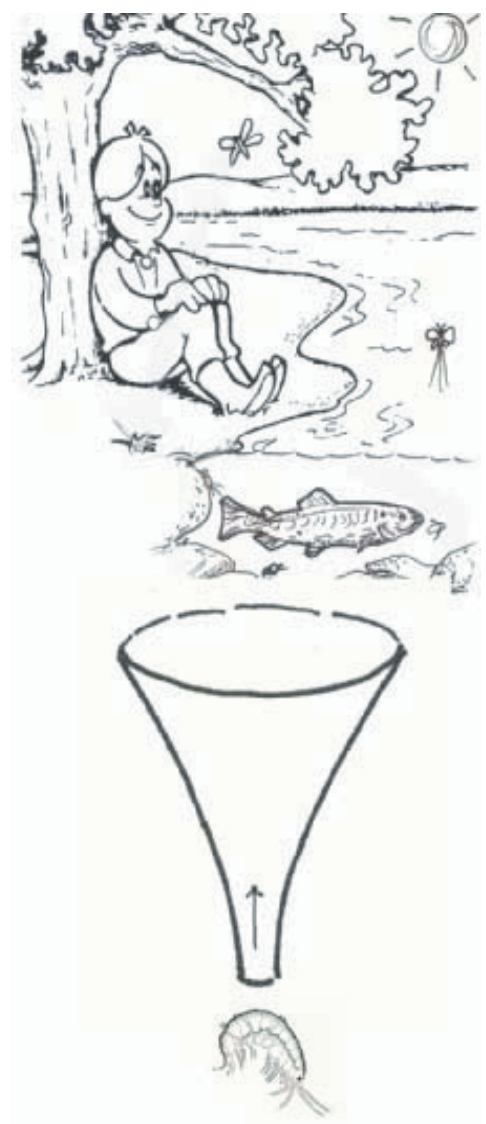

Figure 1. The teaching sequence from the freshwater shrimp to systems ecology and reading nature. The text describe the four phases in the bottom-up perspective. 
Phase 3: Synecology (i.e. the ecological relationships of a community) was discussed and the students were introduced to models of food webs and food pyramids based on the organisms observed in the river. A litterbag experiment was conducted where the children put freshwater shrimps and water louse (Asellus aquaticus.) in small net-bags together with green and brown alder leaves. The bag was then put into the river. After a week it was collected and studied in order to find out if the animals preferred brown leaves and could be considered decomposers in the ecosystem.

Phase 4: Systemic view: (i.e. the relation between biotic and abiotic components and the flow of energy and cycling of matter in the ecosystem). A systemic view of the ecosystem was discussed and students were introduced to photosynthesis and energy flow in the ecosystem by discussing plants ecosystem functions and by building a model of a food pyramid. Photosynthesis and respiration was illustrated by LEGO pieces in an attempt to show that the same three types of atoms were cycling in the ecosystem. The sealed ecosystems were opened and examined. The relation between abiotic and biotic factors was discussed and investigated focussing on the importance of fast water flow for aeration of the water and the importance of trees both for the main food source and for the shadow keeping water temperature low and subsequently oxygen level higher. The importance of a varied bottom substrate for a higher biodiversity was studied together with the direct and indirect human impact on the river ecosystem.

\section{RESULTS}

Two weeks before the interviews, the respondents received the CD-ROM together with a questionnaire. They were asked to fill in the questionnaire and prepare to discuss the questions. The three questions are presented together with an overview of all teachers comments together with quotes from the three selected respondents; R1, R9 and R12.

Question 1. The teaching sequence a)- what do you see as the most important factors influencing students motivation to learn in this teaching design? Rank your answers.

b)- what possibilities and problems do you see in implementing this teaching design in the everyday school situation?

Question 2. What is your view of the impact of the outdoor context for learning ecology?

Question 3. What is your view of 'reading nature' as a goal in science education?

\section{1 a: The most important factors influencing students' motivation to learn in the film?}

The list of factors varied in length between the respondents and we have chosen to present only the top-three factors from each respondents. As we see in the table 1 there were basically only three factors mentioned by all the respondents: The role of the teacher, the authenticity of the studied object and the structure of the teaching.

Table 1. Factors influencing students' motivation to learn.

\begin{tabular}{lllll}
\hline Factor & Ranking & 1 & 2 & 3 \\
& & 8 & 3 & 2 \\
\hline The teacher & 4 & 5 & 3 \\
\hline The authenticity -"the real hands on experiences" & 1 & 5 & 6 \\
\hline The structure of the teaching sequence & - & - & 2 \\
\hline Other & Number of respondents & 13 & 13 & 13 \\
\hline
\end{tabular}


The first factor mentioned by eight of the respondents was the role of the teacher. "He is a very inspiring person and he triggers their curiosity"(R9) or "He is very involved and he takes an active part in the activities supporting the kids, that is the main reason" (R12). The third respondent (R1) combined the importance of the teacher with the importance of the teaching design.

"What is actually going on in the film? -well, it arouses such a curiosity and they can observe and investigate. The teacher is most important because he asks questions and challenges them and their ideas all the time which is highly important. And also that you kind of revise the knowledge constantly by working in different contexts and in different ways with the same thing which is good and in the end you come to realise the whole. The teacher is most important but also the teaching design with the variation where you explore nature, read about it, have games about it and do experiments. This structure is very important"(R1).

The main reason for regarding the teacher as most important had to do with his ability to inspire and trigger students' curiosity. Five respondents also mention the importance of him being a new acquaintance for the students. This novelty effect is well documented in other studies but normally declines after a few lessons (e.g. Gay 1987). The second most important factor for student motivation was the first hand experiences with nature. What R9 said was representative for most of the nine respondents considering this to be of highest or second highest importance: "It is so important to have the first hand experiences of reality- you have to go out and study the real thingthat is important". This aspect will be discussed further in question 3. A clear structure is another argument where R9 said: "the bottom-up design is a wise way of doing it. I haven't tried this but I can see that it works well". The combination of enthusiasm and a well planned teaching sequence offering opportunities for first hand experiences are the most important factors according to the whole group.

\section{1b: What possibilities and problems do you see in this design regarding its implementation to the everyday school situation?}

In question $1 b$ they all noticed that the whole class seemed highly motivated for doing most of the different tasks they worked with, particularly in the early parts of the sequence, where the focus was on the animals and their autecology. In the interviews the respondents brought up five main aspects which could be viewed as either a support or an obstacle for this type of teaching.

Table 2. Different aspects supporting or hindering implementation of the teaching design in the everyday school. The aspects are listed in order of importance for the respondents

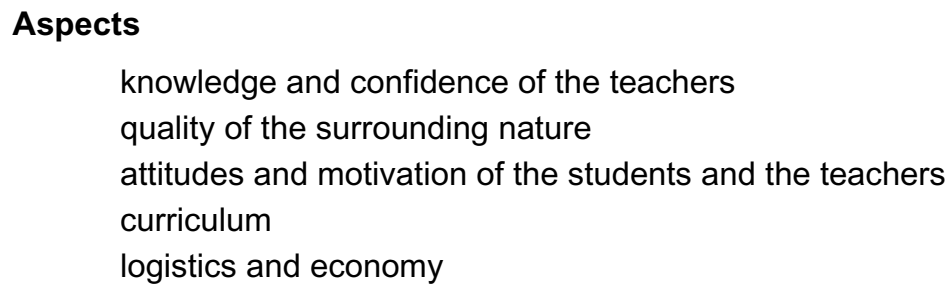

All respondents discussed the importance of content knowledge (biology) and of the confidence and experience of field studies. Nine of them said that the most important for them was the confidence with the methods of outdoor education rather than content knowledge. They said they had enough confidence to try to follow such a teaching sequence. These respondents believed that lack of experience is the most important hindrance for its implementation in primary schools. 
"It is an inspiring method, open, and you are forced to engage in children thinking. Here are all possibilities but also obstacles because you never know where you will land. The teacher is very important. It takes a lot of the pedagogical- knowledge, commitment, inspiration. Without this it won't work. It is easier to tell this by the white board but then they don't learn very much. There has been a strong development among us teachers. From being restricted to the school book and teacher's desk it has changed. I work very differently today. For example, the lapwing, and how we now concentrate on one bird and look at it and draw it and find it in its habitat. This gives you other knowledge-more knowledge but you have to be much more alert. Knowledge is important but the key to it is to listen to the children and work with their questions. The knowledge of the method is most important. I am not a nature expert but I feel confident in doing these type of studies" (R9).

R12 agreed with R9 in the discussion about teacher knowledge but also stress the problems with students' lack of basic knowledge.

"It is more up to ambition than to knowledge. If you can be outdoors and you have the interest you will get far. But the teachers don't know how to do. That is the largest limitation. But today I have only three Swedish students in the whole class. I mean what is an elk? Yes, they don't know anything about our nature and that is a large difference. They haven't walked in nature with mum and dad. But in a school with fewer immigrants it is easier today than before to take the kids out if you want to" (R12).

All respondents argue for the importance of knowledge which gives the confidence to teach and the majority stresses the procedural knowledge and teaching experience as most important. As opposed to the respondents above, however, R1 together with three other respondents say that content knowledge is the most important.

"It has to do with content knowledge more than pedagogical knowledge. My experience from seeing many classes and their teachers is that this is the most common reason for not going out".

In general this selected group regards their level of knowledge as a possibility rather than an obstacle for implementation in their school activities. One example of this is

"If you are not a nature person you cannot do this type of teaching without training in it. It takes a lot of preparation, knowledge and commitment to make it work as it does in the film. You put a lot of effort into a few studies like the one in the film but you cannot do this all the time. You need clear goals and the most important is to give the children the opportunity to find the little, little thing and study it in great detail. This is how they gain respect for nature. You really touch them when you work like this. The limitation is probably that you really have to be committed to it and it must show that this is important to learn (R1).

Despite their own confidence regarding fieldwork, seven respondents were concerned about the general status in schools and particularly among the student teachers they met. This has implications for teacher training which will be discussed in the final section of this paper.

\section{Quality of the surrounding nature}

The second most common factor brought up was the lack of "high quality nature". The majority believed that many of their colleagues found this to be an important reason for not going out. Ten of the respondents said that they did not see this as a large problem for themselves. This is exemplified by the R9's comment:

"In our municipality there are often good alternatives to the river ecosystem and with experience you can even study a school yard". 
R1 said:

"It is not the quality of nature in the first place, but it has to do with planning. We used to go out in a forest once a week but our students got bored in the 'real' nature because you, ee well you cannot expect them to just enjoy a walk in nature. You need to plan better than we did.

This refers back to the confidence and knowledge that can overcome the lack of access to 'real' nature, but for many teachers it can be of vital importance preventing field work, according to the respondents.

\section{Attitudes}

On the one hand it had to do with students attitudes where all the respondents commented on the high motivation of this age group. As R9 said: "The main possibility is that students at this age often find it interesting to do nature studies". The general view was that older students were less interested or at least it was harder to inspire them to do fieldwork, whereas younger students than these had to learn to be outdoors before it was worth starting with ecological theory. R12 referred again to immigrant students: "Many young pupils today compared to before are afraid of nature and this obstacle has to be overridden before teaching ecology can start, otherwise it is not fruitful".

Teachers' attitude was another issue. R1 together with three other respondents said that without knowledge and confidence it is very hard to motivate oneself as a teacher to do this kind of activity.

"And it will not be successful if you are not highly motivated yourself. Since you have all the school subjects as a teacher you cannot expect all the teachers to love this part of their job"(R1).

\section{Curriculum}

All of the respondents referred to the curriculum as a support and not an obstacle for this kind of teaching. They referred to paragraphs such as "students shall be familiar with the common plants and animals and their basic environmental demands", or "students shall be aware of the conditions for a good environment and understand basic ecological conditions for life". They also referred to more open goals in the curriculum stressing the general school work where the students should meet different contexts for learning where they have to cooperate, to discuss, to hypothesise, or to be curious.

Their view was that basically all teachers in their municipality met the curriculum demand and taught about the common plants and animals in the nearest surroundings. Regarding the autecology the six respondents who worked as part time educational support believed that only a few teachers discussed the ecology of these plants and animals.

Six of the respondents were concerned about the recent change in priorities with a much stronger focus on the three core subjects Maths, Swedish and English. From compulsory school a pass in these three subjects is a prerequisite for upper secondary school. "In the schools today there is a priority on the three and that leaves the other less important. This can have a negative impact for the attitude towards this type of teaching" (R9). In line with this R12 said: "We work very much with the Swedish language now. This takes time from everything else".

\section{Logistics and economy}

When the respondents discussed possibilities they often referred to the flexibility in the school day in primary school. As an example R9 said: "Another possibility is that time is not limited at these ages and the schedule is not so structured. It is easy to find half days for these type of activities". 
The respondents came up with examples of a practical kind and the major obstacle, mentioned by seven respondents, was that the classes were large and normally there was only one teacher in the class. Proper clothing was another common problem. One example was about rubber boots. "Some kids simply don't have them and then you can't force them to buy them and the school cannot buy them" (R1).

Two respondents spontaneously mentioned that they were worried about taking classes of thirty students out as a single teacher. The reason was not safety in the first place but had more to do with discipline.

According to the majority of respondents there are many factors in primary school supporting field studies. The flexibility in the time tables, the positive attitudes from students and the curriculum supporting these types of studies are some of them.

Lack of quality nature, lack of experience and interest in nature studies together with economical limits can on the other hand be insurmountable obstacles hindering fieldwork in some classes.

\section{2: The importance of the outdoor aspect for learning ecology.}

All of the 13 respondents argued that field studies are essential and necessary for ecology education in this age group. They often stressed the importance of the combination of fieldwork and indoor activities. This can be exemplified by the following comment:

"both the outdoor and the indoor activities are important. To catch the animals yourself gives a completely different experience compared to if the teacher brought the animals to the class. But to work with the material is easier to do indoors and often students concentrate better indoors" (R12).

This comment also touches on the value of first hand experience which is an aspect of fieldwork. The three most important aspects are listed in table 3.

Table 3. The Respondents main arguments supporting fieldwork in ecology education.

$$
\begin{aligned}
& \text { First-hand experience } \\
& \text { multiple senses } \\
& \text { episodes }
\end{aligned}
$$

\section{First hand experience and multiple senses}

This argument has to do with the importance of studying the real thing and not second hand information in books or in computerized form. As R1 put it:

"Yes, I believe it is very important to be both in- and out of doors for the understanding and for the feeling. You need first hand experiences. To touch it, hold it and listen to it and feel it. Otherwise I'm here and the nature is out there. If you have been out and tried this you can compare and you have references when you come out in different types of nature. Otherwise it will be as it was when I went to school. You studied the book and you copied things down in a workbook. You drummed it into your head and I can't remember anything of it today. But it is completely different in our schools today. Imagine all the time wasted by this way of teaching"(R1). 
In this quote both the firsthand experience and the multiple senses are mentioned. If we compare the comments from R1 and R 9 below they hold the same features regarding first hand experience and multiple senses.:

"You need to use many senses which you do when you are outdoors like on the film. You need to smell it and feel it to get a better feeling for the topic. It is easier to understand the ecology when you have been there- smelling it, seeing it and hearing it. You hook everything up in a different way when you experience it with all senses. You must have walked in the moss to be able to understand the forest (R9).

In the same vein R 12 said: "When you move indoors you loose the important context. Indoors you can never involve all the senses which are important for the learning".

These types of axiomatic statements are common. In follow up questions when the interviewer asked them to define why they believed this, they referred to feeling rather than facts:

"Well it is my strong conviction but I cannot tell you exactly why. I mean that is just the way I believe it is. I haven't tested it. I mean who remembers a film? But when you have been out there and seen it live it is so different. I can only refer to myself and what I have seen in my classes" (R9).

These statements reveal some of the respondents' epistemological view where learning has to do with combining different sources of information and involving many senses. They also reveal an interesting view regarding the object of learning. As we see it their object of learning involved more than the theoretical ecological content knowledge. It also included the affective components, such as feelings, smells or fascination as part of the object of learning.

\section{Episodes}

Five of the respondents said that it is very effective to relate back to the outdoor experiences from fieldwork. They meant that these types of experiences are easy for the children to remember. One of the respondents referred to an event which may illustrate this.

"as an example of how strong these memories are I recently met an old student of mine and she spontaneously started to talk about the memories of a field study event when the whole class studied the chaffinch. It was challenged by a stuffed chaffinch and a tape recorder playing its song. This was more than ten years ago and she remembered it clearly. And it was the first thing she said when she saw me" (R10).

If we look at what the respondents said about episodic memory. There seemed to be a consensus among the five respondents about the effectiveness of strong experiences from the outdoor environment for motivation and retention. It was expressed as:

"You remember an experience more than just words. You get it home by experiencing it in reality. You need to know how it smells and feels in the forest before you talk about it. You need to be at home but it doesn't say anywhere in the curriculum even though we know that this is of key importance for this learning" (R9).

Along the same line R12 said:

"When you have experienced it together you can always refer to it during teaching long after. And you can do it the other way round. I remember when we prepared for an excursion and I showed the class the yellow wagtail in the book and we talked about it. Then we saw it in the field and the class was stunned by its beauty and they talked about the bird often after that".

The stimulation of multiple senses together with fascinating experiences in nature was claimed by eleven of the respondents, to be of greatest importance for the learning and not the least for retention of knowledge. They believed that the film showed plenty of memorable episodes stimulating students' learning. 


\section{3: Reading nature as a goal in science education.}

Reading nature is our own concept (Magntorn \& Helldén, 2005) and as we defined it in the introduction it has to do with the ability to identify the organisms and to relate them to their ecology and their roles in the whole ecosystem. This demands for field studies and encompass relevant knowledge on the levels of taxonomy, autecology and synecology with ideas about cycling of matter and flow of energy in the ecosystem to be read. The main focus with primary school students lies in taxonomy and autecology but the other levels are also part of the teaching sequence and therefore part of the film.

Ten of the respondents found the aim of reading nature good or promising. Three respondents saw it as too difficult and too demanding. Among these three was R12 who said

"we go out on our nature walk once a week and we study everything we see, not only nature. We look at the trees and sometimes birds or flowers but no, I don't link it so much to ecology. The focus is more on naming and recognition. But of course we could do much more of it like on the film but no I don't do that. I think it is much more complicated and maybe too difficult for my students".

What R12 said in the quote above echoes the response to question $1 \mathrm{~b}$ where only six respondents believed it was common to discuss the ecology of the common plants and animals.In the excerpt below R1 discuss how to tackle the link between taxonomy and autecology:

R1: "The film is a proof that it is possible to connect the organisms to their function. But I believe it is difficult for the teachers to do it. Yes, species knowledge is not valuable knowledge if you don't know anything about them. But I mean, look at the curriculum. It is easy to get stuck with species knowledge and not move further. // But I believe it is possible to follow the curriculum and also discuss the demands of the organisms. If you demand reading nature in the curriculum we might move from learning about nature to reading nature which is a big difference.

Interviewer: How do you mean?

R1: Yes it is not only about names and recognition but how to understand the whole, kind of. But the schoolbooks have to be a support. They have to be written to combine the separate parts in a way that helps the teacher to teach this way. Otherwise it would be too difficult. Schoolbooks today don't tie it together. They may start with the plants in the meadow but they don't tie it to ecology. This must change".

The most problematic part of the concept seemed to be the synecological and more abstract components or reading nature. All of the respondents had noticed a decrease in student's interest and focus when the teacher discussed and illustrated the cycling of matter. All thirteen believed this to be the most difficult part for the students but they had different views on whether it should be included or excluded from ecology education for this age group. In the excerpt below R1 expressed the idea that the principle of energy flow is worth mentioning but not the cycles of matter and the process of photosynthesis:

"You need to know a bit to be able to discern the system. You need to explore the diversity first. You need to have names for the organisms before you can move on. After we have worked with the nature school about spiders or trees it is such a joyful expectation among the children when we are going out. Species knowledge and ecology should be linked but the question is when this linking should take place? I believe you need to do this all the time and it is not a bad idea to introduce the terminology and the more abstract processes early, like the energy"(R1).

Eight respondents (including R1 and R12) said that this is not relevant for these young students, since they believed they are not ready to learn this. Two of the respondents were not certain about this and three (including R9) said that they believed it was important to mention the concepts early hoping that some students gained from this when they were confronted with this theory in secondary school. 


\section{DISCUSSION AND IMPLICATIONS}

In such a small study as ours with teachers not chosen at random, questions must be raised concerning generalisation and application. The generalisations made consist of summaries and quotations interpreted and selected by the researchers. It has never been the idea to extrapolate and draw on the results as representative for a larger population but we believe the results can be useful if the reader can relate to them out of personal experience. The fact that there is often consensus or strong majorities in favour of specific views regarding didactical and practical issues adds to the reliability of the results from such a limited group of teachers. If we compare our results about the limitations and promises of fieldwork, with the findings in the large review of research on outdoor learning (Rickinson et al., 2004) there are some interesting points of difference. According to the review the main concern and fear was about young people's health and safety. Another major concern was the problem with access to nature. In our study the safety aspect was not mentioned by any of the respondents and the main view about access to nature was that it was possible to do fieldwork within the near environment of all the primary schools in the municipality. Why are there such differences in viewpoint? Regarding the quality of nature, this may well have to do with the varying degree of urbanization where the access to 'quality nature' in the municipality is relatively good. Another reason might have to do with the influence of the nature school where one of the fundamental ideas is to primarily study nature in the near surroundings of the schools. Despite their lack of specialisation in science the positive experiences from these nature studies might have influenced the respondents' attitudes towards field work even outside 'quality nature'.

Regarding the safety aspects in Sweden this debate has not at all been as intensive as for example in the UK and in the US. Tragic accidents during outdoor education in these two countries started a debate about safety, which has had a negative impact on the attitude towards all fieldwork (Rickinson et al., 2004). It is important to distinguish the wider concept outdoor education, which often holds aspects of outdoor adventures such as climbing or canoeing, from the type of fieldwork conducted in this study. In our teaching design the idea was to combine a strong focus on content knowledge with practical studies involving multiple senses.

Learning science means learning to talk science (Lemke, 1993). Each scientific discipline has its own semantics and learning to name the common organisms and to express relationships between the organisms and their environment is of key importance in reading nature. This literacy comprises not only semantics but also first hand affective experiences or as R9 put it to "feel at home" and to experience the river with many senses. The importance of combining affection and cognition is supported by Nundy (2001) who studied the relationship between affective and cognitive domains and concluded that gains in one domain reinforce gains in the other. Earlier in the paper we quoted one of the respondents mentioning a former student who after more than a decade still remembered clearly an occasion with a stuffed chaffinch and a tape recorder. This episode carried enough importance for the student to be integrated in her memory, or cognitive structures, for several years. This can be applied to the positive experiences from well prepared field work. The importance of fieldwork styles for long term memory structures was studied by Mackenzie and White (1982). The researchers found a positive correlation between fieldwork and learning in general but in particular they found that excursions or fieldwork which encouraged processing and produced strong linking of episodes with content knowledge improved students understanding in general but their long term retention of knowledge significantly. Narratives and personal relation to the scientific content is considered an important aspect of cognitive science and scientific literacy (Klein, 2006) and the concept reading nature certainly is an example of this. Reading nature has to do with discerning structures in nature such as plants, animals, rocks or litter, and to make up a relevant narrative about the ecosystem based on what they know about the ecology related to these structures in the nature to be read. 
In the review mentioned earlier the curricula and the time table where viewed as hindering fieldwork (Rickinson et al., 2004). This was mainly the case in secondary schools, and likely to be the same in Sweden. In our study these factors were rather seen as support for fieldwork. In primary school in Sweden there is often one teacher in the class who teaches all theoretical subjects over at least three years. The Swedish curricula for science is, in comparison with National Science Education Standards (National Academy of Sciences, 1996) rather more open for interpretation and not as concrete and detailed. This leaves the teacher with less guidance and a more free hand in prioritising the content. The fact that students in Sweden get their first grades in year eight might also be an aspect where primary teachers can make their own priorities. The problems noted by the respondents were the lack of explicit stress on the outdoor environment as the place for instruction. The other concern dealt with a growing domination of the three school subjects, maths, Swedish and English. Several respondents saw this as a recent and rapid change affecting all other subjects in school. We see it as unfortunate if we move towards a three-subject school in Sweden, especially during primary school when the curriculum and time table open up for out of classroom activities and the young students are still enthusiastic about this.

Another major challenge according to the review (Rickinson et al., 2004) was teachers' lack of confidence and expertise in outdoor teaching where a study of Chicago primary schoolteachers' willingness to use outdoor natural settings for environmental education found that the teachers did not believe that they were particularly well trained to teach in natural areas. They believed their classes were too large to manage and that they lacked the necessary content knowledge to teach in such places (pp. 43). In our study the respondents also pointed at these challenges but it is interesting to notice that the majority considered their own methodological knowledge more important than the content knowledge. On the other hand they often assumed that insufficient content knowledge was the main reason for colleagues not doing field work like on the film.

The maybe greatest concern was the voices raised about the next generation teachers' lack of knowledge and of confidence in this field. This is supported by studies elsewhere. For example in the UK, Barker et al. (2002) point out that "the decline in fieldwork is also evident in initial teacher training [...and...] in-service experience is becoming less likely". We believe it to be of great importance to involve both theoretical and practical aspects regarding fieldwork in teacher training. There is a motivated anxiety about fieldwork where several of the respondents stress the worry about loosing the control, a situation they find less likely to take place in the classroom. As Rickinson et al. (2004) stress, "Poor fieldwork is likely to lead to poor learning. Students quickly forget irrelevant information that has been inadequately presented. Fieldwork has to be well planned and executed". We believe it to be unfair to demand for fieldwork without giving the teachers the proper tools for it. Proper fieldwork does not only deal with environmental and ecological content knowledge but of course it also involves several other skills demanded for in the national curriculum such as cooperative skills and curiosity etc. Without confidence it is difficult to be the source of inspiration and motivation. We believe it to be important to include training in reading nature both as a concept, with its ecology content, but also as a method in the teacher training.

The combination of being competent in how to encourage and inspire students during field work has to be combined with the relevant ecological knowledge. One of the keys to successful instruction is that the teacher has enough experience to select the relevant organisms in the ecosystem to be read. Teaching for reading nature is not about describing all the things you find in nature but rather to help the students to discern the key organisms and the specific conditions governing the ecosystem to be read.

We also want to stress the importance of starting early with this type of instruction. As all the respondents have mentioned, this age group is good to work with. This is supported by a large study on students' perception of learning in natural environments where they found significant differences between the primary and secondary school age group where primary school students 
were found to be significantly more enthusiastic than their secondary counterparts both before and after the experience (Ballantyne \& Packer, 2002). This enthusiasm together with the logistic advantage in primary school, mentioned above, support our belief that it is important to involve the young students in this type of education in primary school. It is easier and not less important to encourage their positive attitude towards nature at these early ages. Later on it may be much more difficult.

In conclusion we found that the majority of the selected teachers had experience based convictions about the importance of first-hand experiences, of involving many senses and of creating structured teaching events beyond just the naming of common plants and animals. The nature school seemed to be an important factor influencing this epistemological viewpoint where the method rather than the content knowledge was regarded as most important. The collected data suggests that teacher training should take into account of a range of factors and processes when encouraging students to be competent and confident users of field work in their teaching. Combining ecological theory with examples of successful teaching design and discussing the object of learning and the importance of the context for ecological understanding, as exemplified on the film, we believe are of great importance. A next generation teachers with a positive approach based on practical and theoretical experiences from teacher training is a very good start towards teaching for 'reading nature' in future classes.

\section{REFERENCES}

Anderson, C.W. \& Hogan, K. (1999). Editorial and call for papers: Design in Science Education. Journal of Research in Science Teaching, 38 (1), 3-16.

Ballantyne, R. \& Packer, J. (2002). Nature-based excursions: school students' perceptions of learning in natural environments. International Research in Geography and Environmental Education 11 (3), 218-236.

Barker, S., Slingsby, D., \& Tilling, S. (2002). Teaching Biology Outside of classroom: is it heading for extinction? A report on biology fieldwork in the 14-19 Curriculum. Shrewsbury: Field Studies Council.

Bebbington, A.(2005). The ability of A-level students to name plants. Journal of Biological Education 39 (2), 63-67.

Dillon, J. Rickinson, M., Teamey, K., Morris, M., Choi,M.Y, Sanders, D. \& Benefield, P. (2006). The value of outdoor learning: evidence from research in the UK and elsewhere. School Science Review 87 (320), 107-113.

Klein, P,D. (2006). The Challenges of Scientific Literacy. International Journal of Science Education, 28 (2), 143-178.

Kvale, S. (1997). Den kvalitativa forskningsintervjun. Lund: Studentlitteratur.

Leach, J., Scott, P.(2002). Designing and evaluating science teaching sequences. Studies in Science Education, 38, 115-142.

Lemke, J. L. (1993). Talking Science. Language Learning and values. Norwood, New Jersey: Ablex Publishing Corporation.

Lijnse, P.L. (2000). Didactics of science: the forgotten dimension in science education research? In R. Millar, J. Leach, J. \&Osborne (Eds). Improving Science Education-the contribution of research (pp 308-326). Buckingham: Open University Press

Mackenzie,A. A. \& White R.T. (1982). Fieldwork in Geography and Long-term Memory Structures. American Educational Research Journal, 19 (4), 623-632.

Magntorn, O., \& Helldén, G. (2005). Student-Teachers' Ability to Read Nature: Reflections on their own learning in ecology. International Journal of Science Education, 27 (10), 12291254.

Meheut, M \& Psillos, D. (2004). Teaching-learning sequences: aims and tools for science education research. International Journal for Science education, 26 (5), 515-535. 
National Academy of Sciences (1996). National Science Education Standards. Washington DC: National Academy Press.

Nundy, S. (1999). 'The fieldwork effect: the role and impact of fieldwork in the upper primary school'. International research in Environmental Education, 8 (2), 190-198.

Orr, D.W. (1992). Ecological Literacy: education and the transition to a postmodern world. Albany: State University of New York Press.

Rickinson, M., Dillon, J., Teamey, K., Morris, K., Choi, M,Y., Sandres, D. \& Benefield, P. (2004). A Review on Outdoor Learning. Shrewsbury, UK: Field Studies Council, 8. National Foundation for Educational Research. 